\title{
Vaccarin attenuates high glucose-induced human EA·hy926 endothelial cell injury through inhibition of Notch signaling
}

\author{
YUYU QIU $^{1 *}$, BIN DU $^{1 *}$, FENGSHAN XIE ${ }^{2 *}$, WEIWEI CAI ${ }^{1}$, \\ YANLING LIU ${ }^{2}$, YUE LI ${ }^{2}$, LEI FENG ${ }^{1}$ and LIYING QIU ${ }^{1}$ \\ ${ }^{1}$ Laboratory of Tumor Pharmacology, Wuxi Medical School, Jiangnan University; ${ }^{2}$ Laboratory of Natural Medicine, \\ School of Pharmaceutical Science, Jiangnan University, Wuxi, Jiangsu 214122, P.R. China
}

Received February 2, 2015; Accepted November 30, 2015

DOI: $10.3892 / \mathrm{mmr} .2016 .4801$

\begin{abstract}
Endothelial cell injury is a critical component of atherosclerosis and hypertension. Vaccarin is considered to be of potential benefit in the treatment of vascular diseases. The aim of the present study was to evaluate the possible effects of vaccarin in human EA.hy926 cells induced by high glucose, and to investigate its underlying mechanism in the prevention and treatment of high glucose-induced injury. In the present study, EA·hy926 cells were exposed to 90,180 and $270 \mathrm{mM}$ high glucose for $24 \mathrm{~h}$, and the induced cell injury was examined using a sulforhodamine B assay. Following treatment with high glucose, it was found that high glucose stimulated cell injury, resulting in reduced cell viability and migratory ability, increased lactate dehydrogenase (LDH) leakage and malondialdehyde (MDA) levels, and decreased superoxide dismutase (SOD) activity. High glucose further accelerated cell apoptosis via activating Notch1 and Hairy and enhancer of split 1. It was found that preincubation with vaccarin protected the EA-hy926 cells from high glucose-induced cell injury, which promoted cell viability and migratory ability, inhibited the expression levels of LDH and MDA, and enhanced the activity of SOD. Cell migratory ability, LDH leakage, MDA levels and decreasing SOD activity were evaluated using a wound healing assay and corresponding assay kits. Cell apoptosis was detected by flow cytometry with an Annexin V-fluorescein isothiocyanate/propidium iodide apoptosis detection kit and Hoechst staining. Furthermore, western blotting was used to detect the protein expression levels of Notch1, Hes1 and caspase-3. In particular, in addition to inducing the downregulation of Notch signaling, vaccarin treatment downregulated the cell apoptotic
\end{abstract}

Correspondence to: Professor Liying Qiu, Laboratory of Tumor Pharmacology, Wuxi Medical School, Jiangnan University, 1800 Lihu Road, Wuxi, Jiangsu 214122, P.R. China

E-mail: qiulydoc@sina.com

*Contributed equally

Key words: vaccarin, human EA•hy926 endothelial cells, high glucose injury, Notch signaling pathway-associated protein caspase 3 . These findings suggested that vaccarin may be able to selectively protect the vascular endothelium from dysfunction induced by high glucose.

\section{Introduction}

Macrovascular diseases, including atherosclerosis, are the most common complications of diabetes (1). Diabetes mellitus impairs endothelial function, which can be considered as the hallmark in the development of cardiovascular diseases (2). The vascular endothelium is considered to be important in diabetes-associated vascular dysfunction, including atherosclerosis (3). The endothelium is critical in the regulation of vascular function, and in the development of physiological and pathophysiological inflammation (4). Endothelial cell injury is a critical component of atherosclerosis and hypertension (5). Studies have indicated that high glucose induces endothelial cell apoptosis, and can cause cellular dysfunction and even cell death $(6,7)$.

The Notch signaling pathway is one of the pathways that is important in cell differentiation, acting primarily to determine and regulate cell survival (8). In mammals, four receptors (Notch1-4) and five ligands, including Jagged 1, Jagged 2, $\delta$-like (Dll) 1, Dll3 and Dll4, have been identified (9). Notch signaling affects cellular activities, including proliferation, migration, growth, differentiation and death (10). In addition, Notch activity controls communication between cells, signal transduction in the cytoplasm and gene transcription in the nucleus (10). The genes downstream of Notch signaling include Hairy and enhancer of split 1 (Hes1) and the Hairy-related transcription factor family (9). The binding of a ligand and receptor induces a conformational change of the Notch receptor, which allows an extracellular metalloprotease to cleave the receptor, inducing the g-secretase-mediated protease to release the Notch intracellular domain. Subsequently, the Notch intracellular domain travels into the nucleus, where it activates the transcription of downstream genes, including Hes1 (11). Previous studies have reported that, in high glucose-induced cell apoptosis, the Notch signaling pathway is upregulated (12), suggesting that Notch inhibition may be a useful method to protect cells from high glucose-induced apoptosis.

At present, the detrimental effects induced by high glucose on human endothelial cells can be suppressed by several types of plant-derived active substances, including radix hedysari 
polysaccharide and (-)-epigallocatechin-3-gallate $(12,13)$. Vaccaria serum, the seeds of Vaccaria segatalis (Neck.) Garcker. ex Asch. (Caryophyllaceae), is a well-known traditional medicinal plant (14), which is used for its effects on the circulatory system to promote menstruation, improve blood circulation, regulate menstrual disturbance and reduce edema $(15,16)$. It contains flavonoids, cyclic peptides, triterpene saponins, lipids, aliphatic acids, monosaccharides, biotin and coumarin $(16,17)$. A number of these compounds exhibit bioactive properties, including anti-angiogenesis, and growth-inhibitory activity on luteal cells, HL-60 cells and endothelial cells (18). Vaccarin is a major flavonoid glycoside in Vaccariae semen. It is considered one of the major active constituents, and has gained increased attention in scientific investigations (19). The present study aimed to investigate the protective effect of vaccarin (Fig.1A) on the EA.hy926 human umbilical vein endothelial cell line injured by high glucose in vitro. The involvement of the Notch signaling pathway in the vaccarin-induced protective effects observed during high glucose-induced cellular injury remains to be studied. In order to further understand whether vaccarin reduced Notch1 and apoptosis in vitro, the role of vaccarin in the reduction of apoptosis in EA.hy926 cells within the range of an effective concentration was evaluated.

\section{Materials and methods}

Materials. Vaccarin was purchased from Shanghai Shifeng Technology Co., Ltd. (Shanghai, China). Sulforhodamine B (SRB) was purchased from Sigma-Aldrich (St. Louis, MO, USA). An Annexin V-Fluorescein isothiocyanate (FITC)/propidium iodide (PI) Apoptosis Detection kit (cat. no. KGA104) was purchased from KeyGEN Biotechnology, Co., Ltd. (Nanjing, China). A DAB kit (cat. no. P0203) was purchased from Beyotime Institute of Biotechnology (Jiangmen, China). Rabbit polyclonal notch1 (cat. no. ab52627; 1:500), rabbit polyclonal Hes1 (cat. no. ab108937; 1:500), rabbit polyclonal caspase 3 (cat. no. ab32351; 1:1,000) and rabbit polyclonal $\beta$-tublin (cat. no. ab6046; 1:1,000) antibodies were purchased from Abcam (HongKong, China). Polyclonal goat anti-rabbit IgG secondary antibody (cat. no. ab10058; 1:2,000) was purchased from Sangon Biotech Co., Ltd. (Shanghai, China). Kits used for the measurement of lactate dehydrogenase (LDH; cat. no. 20130620), methane dicarboxylic aldehyde (MDA; cat. no. 20130608), super oxygen dehydrogenase (SOD; cat. no. 20130618) and bicinchoninic acid (BCA; cat. no. 20130619) concentrations were purchased from the Institute of Jiancheng Bioengineering (Nanjing, China). M-PER Mammalian Protein Extraction Reagent was purchased from Thermo Fisher Scientific, Inc. (Waltham, MA, USA).

Cell culture and treatment. Human EA·hy926 endothelial cells (cat. no. CRL-2922; American Type Culture Collection, Manassas, VA, USA) were cultured in Dulbecco's modified Eagle's medium (DMEM; (GE Healthcare Life Sciences, Logan, UT, USA) supplemented with $10 \%$ fetal calf serum (Gibco; Thermo Fisher Scientific, Inc.) and incubated at $37^{\circ} \mathrm{C}$ in a humidified air containing $5 \% \mathrm{CO}_{2}$.

Prior to induction with high glucose, the cells were grown to $80-90 \%$ confluence and placed in $2 \%$ serum-containing media for $12 \mathrm{~h}$ to achieve cell synchronization. The vaccarin solution was diluted $(3.44,6.88$ or $13.76 \mu \mathrm{M})$ with culture medium immediately prior to the experiment. The cells were treated with glucose in the absence or presence of vaccarin. The cell monolayers were pretreated with vaccarin $(3.44,6.88$ or $13.76 \mu \mathrm{M}$ ) at $37^{\circ} \mathrm{C}$ for $24 \mathrm{~h}$, followed by being induced by glucose. Following treatment with glucose, the cells were maintained in $10 \%$ serum-containing media in a $5 \% \mathrm{CO}_{2}$ atmosphere at $37^{\circ} \mathrm{C}$ and used for further experiments.

Analysis of cell viability. An SRB assay was performed to assess EA·hy926 cell viability (20). The EA·hy926 cells were seeded into 96-well culture plates, with four replicates for each concentration. Culture of the cells in medium was continued for $24 \mathrm{~h}$, following which vaccarin solution at three final concentrations $(3.44,6.88$ and $13.76 \mu \mathrm{M})$, dissolved in serum-free medium, were added to each well. Following $24 \mathrm{~h}$ incubation at $37^{\circ} \mathrm{C}$, glucose solution $(90,180$ or $270 \mathrm{mM})$ dissolved in serum-free medium were added to each well and continued to culture for 12 and $24 \mathrm{~h}$. The medium was then removed and $5 \%$ trichloroacetic acid (TCA; Sinopharm Chemical Reagent Co., Ltd., Shanghai, China) was added to each well for $200 \mu \mathrm{l}$ to fix the cells for $40 \mathrm{~min}$ at $4^{\circ} \mathrm{C}$. The TCA solution was then removed and replaced with $100 \mu \mathrm{LRB}$, and the cells were incubated at $30^{\circ} \mathrm{C}$ for $30 \mathrm{~min}$. Following removal of the SRB, the samples were washed with deionized water twice. Finally $10 \%$ tris hydroxymethyl aminomethane (Tris; Sinopharm Chemical Reagent Co., Ltd.) was used to dissolve the SRB, and the samples were shaken for $30 \mathrm{sec}$ twice at room temperature. The results were determined at $540 \mathrm{~nm}$ using a Multiskan MK3 reader (Thermo Fisher Scientific, Inc.), with the cell viability expressed as an optical density (OD) value. In addition, the cell morphology was observed under an inverted/phase contrast microscope, and images were captured at 200x magnification using a Nikon Eclipse Ti microscope (Nikon, Toyko, Japan).

Wound healing assay. The migration rate of the cells was measured using a wound healing assay (21). Briefly, the EA•hy926 cells (8x10\%/well) were seeded into wells and were cultured at $37^{\circ} \mathrm{C}$ in a saturated humidity containing $5 \% \mathrm{CO}_{2}$ for $24 \mathrm{~h}$. When the cells had attached completely, a line was scaped through the middle of the cell plate, measuring $\sim 1 \mathrm{~mm}$ in width, following treatment with vaccarin $(6.88$ and $13.76 \mu \mathrm{M})$. The cells were incubated, and images of randomly-selected fields were captured at 100x magnification under a microscope video system (Nikon Eclipse Ti; Nikon). The mean distances between the two ends of the scratch were quantified by manual measurements, and the migration rate was calculated with the control defined as $100 \%$.

Measurement of $\mathrm{LDH}$ release, and intracellular SOD and MDA content. LDH, an indicator of cell injury, was detected using an assay kit, according to the manufacturer's protocol, with the activity of the enzyme expressed as units per liter, and the absorbance was read at $450 \mathrm{~nm}$ using a Multiskan MK3 microplate reader (Thermo Fisher Scientific, Inc.). As described previously (22), the activities of SOD and MDA were determined using commercially available kits, according to the manufacturer's protocol, with enzyme activities expressed as units/mg protein. A single unit of SOD activity 
$\mathbf{A}$<smiles>O=c1cc(-c2ccc(O[C@@H]3O[C@H](CO)[C@@H](O)[C@H](O)[C@H]3O)cc2)oc2cc(O)c([C@H]3O[C@H](CO)[C@@H](O)[C@H](O)[C@H]3O[C@H]3OC[C@@H](O)[C@H](O)[C@H]3O)c(O)c12</smiles>

B

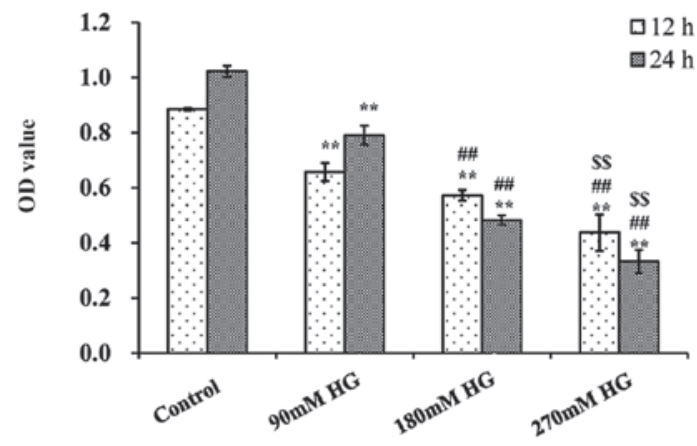

C
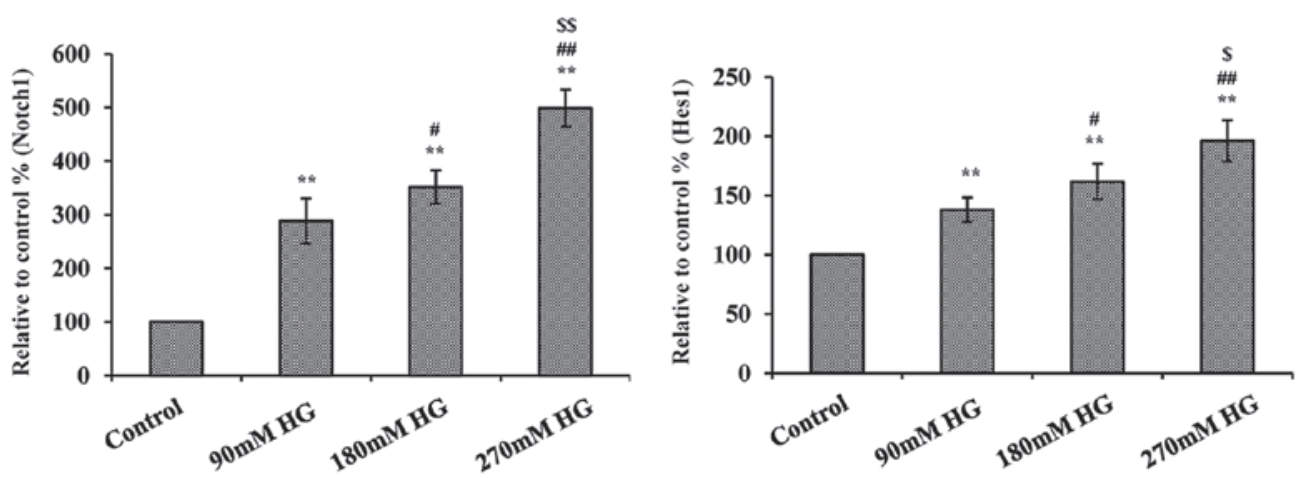

Figure 1. Chemical structure of vaccarin and effects of high glucose on cell viability and the expression levels of Notch1 and Hes1 in EA-hy926 cells. (A) Chemical structure of vaccarin. (B) Viability of EA.hy926 cells was assessed by performing a sulforhodamine B assay, with the viability expressed as an OD value. (C) Representative images and quantitative data from the results of Western blot analysis following treatment for 24 h. The results are expressed as the mean \pm standard deviation $(\mathrm{n}=4) .{ }^{*} \mathrm{P}<0.05$ and ${ }^{* *} \mathrm{P}<0.01$, compared with the control group, ${ }^{\#} \mathrm{P}<0.05$ and ${ }^{\# \#} \mathrm{P}<0.01$, compared with the $90 \mathrm{mM}$ HG group; ${ }^{\$} \mathrm{P}<0.05$ and ${ }^{\$} \mathrm{P}<0.01$, compared with the $180 \mathrm{mM}$ HG group. HG, high glucose; Hes1, Hairy and enhancer of split 1; OD, optical density.

was defined as the quantity, which reduced the absorbance at $450 \mathrm{~nm}$ by $50 \%$. The measurement of BCA was performed prior to determining the SOD. Levels of MDA were measured at $532 \mathrm{~nm}$ by its reaction with thiobarbituric acid to form a stable chromophoric product, with MDA levels expressed as $\mathrm{nmol} / \mathrm{mg}$ protein.

Cellular apoptosis assay. The EA.hy926 cells were prepared for analysis, according to the manufacturer's protocol of the Annexin V-FITC/PI Apoptosis Detection kit. The stained cells were quantitatively detected using a FACScan flow cytometer (BD Biosciences, San Jose, CA, USA) in the FL1-H and FL2-H channels. Data were analyzed using CellQuest Pro software version 6.0 (BD Biosciences), with a total of 10,000 cells analyzed.

Hoechst staining. In a $24-w e l l$ plate with cover slips, $6 \times 10^{4}$ EA•hy926 cells were seeded into each well and cultured for $24 \mathrm{~h}$, following treatment with different doses of vaccarin (6.88 and $13.76 \mu \mathrm{M}$ ) for $24 \mathrm{~h}$ prior to being subjected to $24 \mathrm{~h}$ glucose $(180 \mathrm{mM})$ induction. Following removal of the culture medium, the cells were fixed with $0.5 \mathrm{ml} 4 \%$ paraformaldehyde (Sinopharm Chemical Reagent Co., Ltd.), and then washed twice with phosphate-buffered saline (PBS). Following treatment with Hoechst33342 (Wuhan Boster, China) for $10 \mathrm{~min}$, the cells were rinsed twice with PBS. The stained cells were immediately observed under a fluorescence microscope (Nikon Eclipse Ti, Nikon, Tokyo Japan).

Western blot analysis. Protein levels were analyzed using Western blot analysis, as described previously (23). Briefly, total protein was extracted using the BCA kit and $25 \mu \mathrm{g}$ total protein/well was loaded onto SDS-PAGE gels (Beyotime Institute of Biotechnology) following denaturing in loading buffer at $100^{\circ} \mathrm{C}$ for $5 \mathrm{~min}$. The protein extracts were subjected to $8-12 \%$ SDS-PAGE and transferred onto a nitrocellulose 
membrane (EMD Millipore, Billerica, MD, USA). Following the transfer, the membranes were blocked at room temperature for $2 \mathrm{~h}$ in $5 \%$ nonfat dry milk/Tris-buffered saline with Tween 20 (TBST; Sinopharm Chemical Reagent Co., Ltd.) and then incubated at $4^{\circ} \mathrm{C}$ overnight with the following primary antibodies: Notch1 (1:500), Hes1 (1:500), caspase3 $(1: 1,000)$ and $\beta$-tublin $(1: 1,000)$. The following day, the membranes were washed three times with TBST for $10 \mathrm{~min}$ at room temperature, and subsequently incubated in secondary antibody (anti-rabbit IgG; 1:2,000) conjugated to horseradish peroxidase for $2 \mathrm{~h}$ at room temperature. Following incubation, the membranes were washed, as above, and the protein bands were visualized using a DAB Advanced Western Blotting Detection kit (Beyotime Institute of Biotechnology). $\beta$-tublin was used as the protein loading control following measurement of the integral optical density.

Statistical analysis. The results are expressed as the mean \pm standard deviation. Statistical analysis was performed using one-way analysis of variance with SPSS 20.0 (IBM SPSS, Armonk, NY, USA). P $<0.05$ was considered to indicate a statistically significant difference.

\section{Results}

High glucose reduces cell viability, and increases the expression levels of Notchl and Hesl in the EA.hy926 cells. In order to investigate the effect of high glucose on EA-hy926 cells in the present study, the cells were induced by high glucose $(90,180$ or $270 \mathrm{mM}$ ) for 12 and $24 \mathrm{~h}$, and cell viability was examined using an SRB assay. As shown in Fig. 1B, treatment with high glucose alone significantly reduced cell viability by $>50 \%$ following $12 \mathrm{~h}$ treatment at $270 \mathrm{mM}$, and following $24 \mathrm{~h}$ treatment with 180 and $270 \mathrm{mM}$ glucose. The OD values in the control group were $0.885 \pm 0.005$ and $1.022 \pm 0.020$ following 12 and $24 \mathrm{~h}$ in culture, respectively. All the groups had a significant decrease in viability, compared with these normal control groups $(\mathrm{P}<0.01)$. These results resulted in the selection of $24 \mathrm{~h}$ treatment with $180 \mathrm{mM}$ glucose for the subsequent experiments. In addition, the present study investigated the expression levels of Notch1 and Hes1 following $24 \mathrm{~h}$ high glucose culture and the results suggested that high glucose treatment significantly increased the expression levels of Notch1 and Hes1 in a dose-dependent manner (Fig. 1C).

Vaccarin increaes the viability and migratory ability of high glucose-injured EA.hy926 cells. The effects of vaccarin on EA.hy 926 cell proliferation were examined following 12 and $24 \mathrm{~h}$ treatment with $180 \mathrm{mM}$ glucose. As shown in Fig. 2A, the cell viability in the presence of vaccarin increased significantly, compared with the groups without vaccarin treatment, respectively $(\mathrm{P}<0.01)$. Vaccarin afforded dose-dependent protection against the reduction in cell viability induced by high glucose concentrations between 3.44 and $13.76 \mu \mathrm{M}$. As observed under the microscope, high glucose treatment resulted in significant cell shrinkage, compared with the control group. However, pretreatment with three different vaccarin concentrations (3.44, 6.88 and $13.76 \mu \mathrm{M})$ attenuated high glucose-injured cell shrinkage (Fig. 2B). Based on these results, pretreatment with
6.88 and $13.76 \mu \mathrm{M}$ vaccarin and $180 \mathrm{mM}$ glucose for $24 \mathrm{~h}$ was selected for use in the subsequent experiments. As shown in Fig. 2C, following treatment with high glucose, the migratory ability of cells decreased, resulting in a migration ratio of $23.16 \pm 2.87 \%(\mathrm{P}<0.01)$, compared with the normal cells. However, vaccarin at concentrations of 6.88 and $13.76 \mu \mathrm{M}$ significantly increased the migration ratio $(50.71 \pm 7.33$ and $82.00 \pm 1.95 \%$, respectively, compared with the high glucose group $(\mathrm{P}<0.01)$.

Vaccarin decreases the apoptotic index of high glucose-injured EA.hy926 cells. The induction of apoptosis was measured by Annexin V/PI double staining. The results of the flow cytometric analysis in the high glucose group showed increase apoptosis. The ratio of prophase and late apoptosis reached $8.66 \pm 0.30$ and $13.35 \pm 1.11 \%$, respectively $(\mathrm{P}<0.01)$, compared with the control group. However, the apoptotic ratio following treatment with vaccarin in the 6.88 and $13.76 \mu \mathrm{M}$ groups significantly declined $(\mathrm{P}<0.01)$, compared with the high glucose group (Fig. 3A).

In the Hoechst staining experiment, it was also found that apoptosis was markedly higher in the high glucose group (Fig. 3B). Following treatment with vaccarin (6.88 and $13.76 \mu \mathrm{M})$, the apoptotic index was significantly decreased $(\mathrm{P}<0.01)$, compared with the high glucose group.

Effects of vaccarin on SOD, $L D H$ release and levels of $M D A$ in high glucose-injured EA.hy926 cells. Treatment of the cells with high glucose for $24 \mathrm{~h}$ decreased the levels of SOD, but increased LDH release and the levels of MDA $(\mathrm{P}<0.01)$, compared with the control group. As shown in Fig. 4, incubation of the EA-hy926 cells in the presence of vaccarin ( 6.88 and $13.76 \mu \mathrm{M})$ with high glucose significantly increased SOD activity (Fig. 4A) and decreased the level of MDA and release of LDH, respectively (Fig. 4B and C). According to these results, vaccarin significantly altered SOD activity, LDH leakage and MDA levels in the high glucose-induced endothelial cells in a concentration-dependent manner.

Vaccarin increases the expression levels of Notch1, Hesl and caspase 3 in high glucose-injured EA.hy926 cells. To further investigate the effect and mechanism of vaccarin of high glucose-injured EA-hy926 cells, the presented study examined the expression levels of Notch1, Hes1 and caspase 3 using Western blot analysis. As shown in Fig. 4D, treatment with high glucose significantly increased the expression levels of Notch1, Hes1 and caspase 3, relative to the control group $(\mathrm{P}<0.01)$. By contrast, in the cells were pretreated with vaccarin $(6.88$ and $13.76 \mu \mathrm{M})$, the expression levels of Notch1, Hes1 and caspase 3 decreased significantly $(\mathrm{P}<0.01)$, compared with the high glucose group.

\section{Discussion}

Endothelial barrier dysfunction is pivotal in the pathogenesis of diabetic vascular complications. Exposure of the vascular endothelial tissue to high glucose causes endothelial dysfunction and further complications of diabetes, including cardiovascular diseases (24). A previous report showed that high glucose induced the production of reactive oxygen species (ROS), which can cause cellular dysfunction, cell apoptosis 


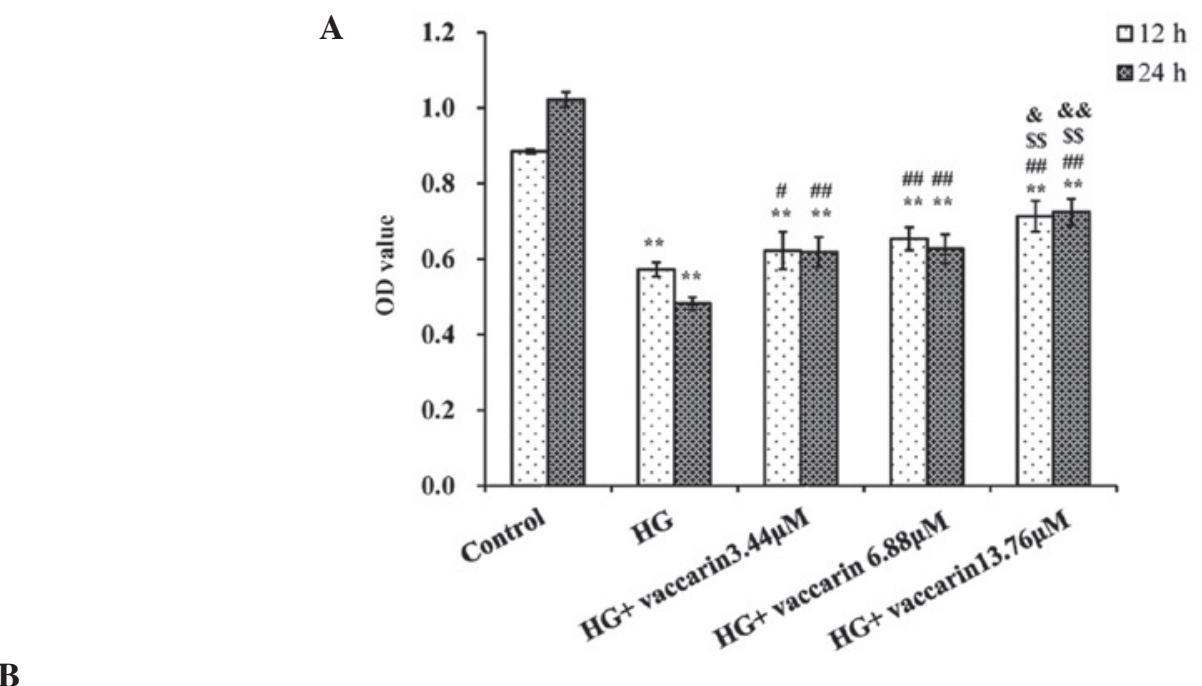

B
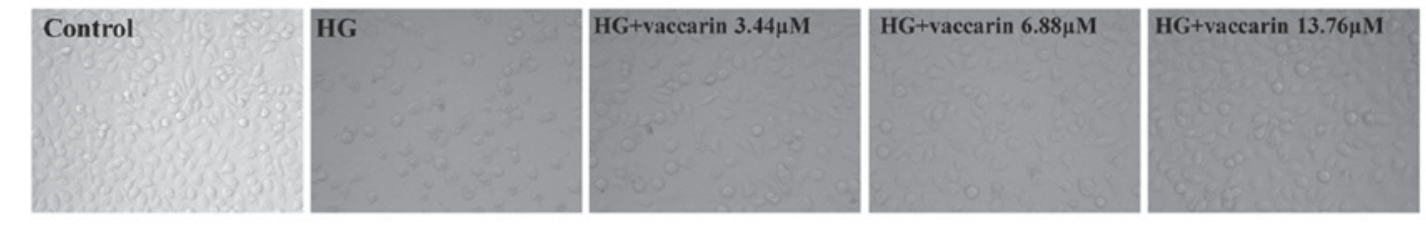

C
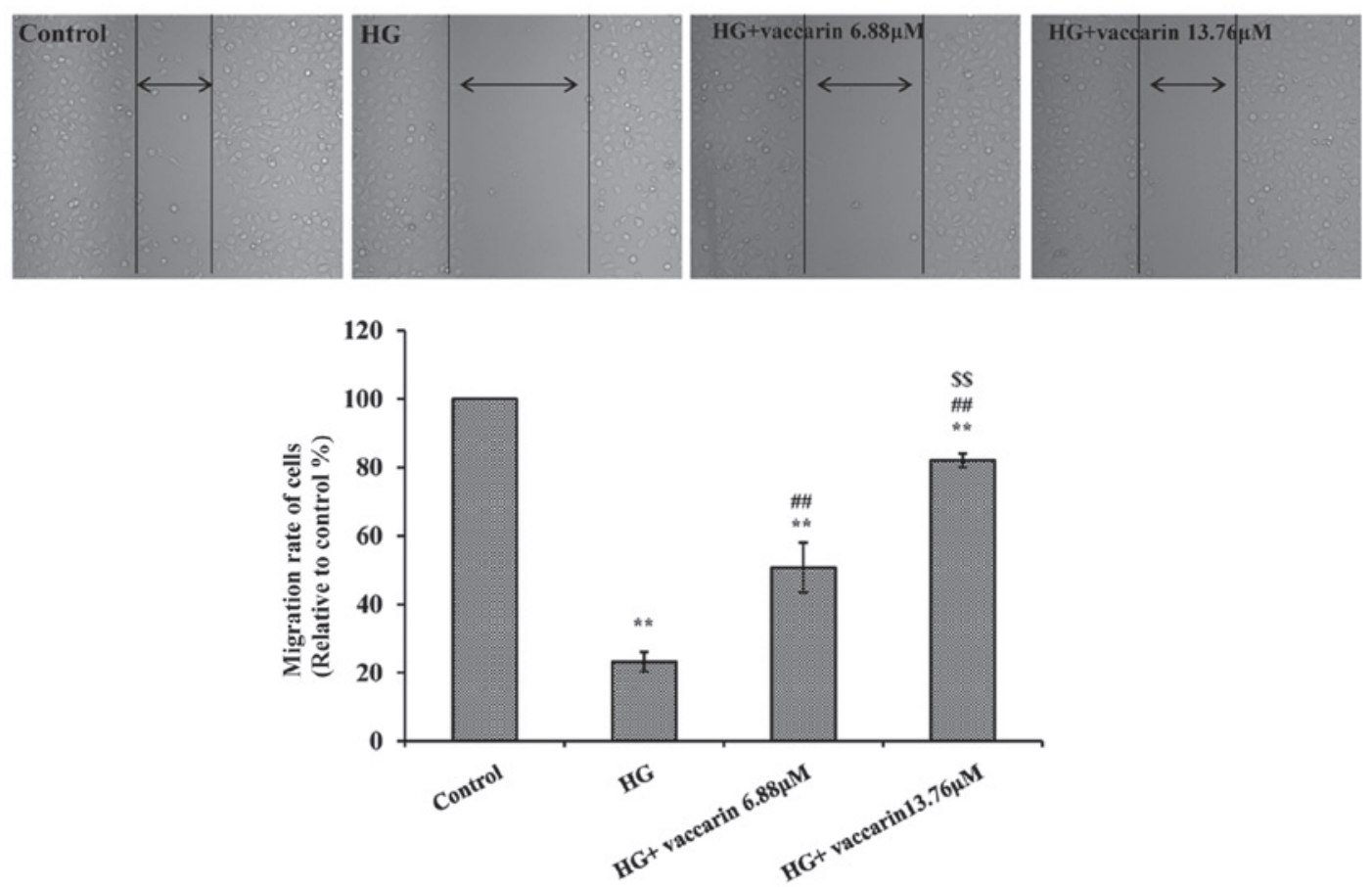

Figure 2. Effects of vaccarin on the viability, morphology and migratory ability of high glucose-injured EA-hy926, treated for $24 \mathrm{~h}$ (180 mM). (A) Viability of EA.hy 926 cells was assessed by performing a sulforhodamine B assay, and the viability was expressed as an OD value. (B) Cell morphology was observed under an inverted/phase contrast microscope, and images were captured. Significant cell shrinkage was observed in the high glucose group, and vaccarin treatment reduced the high glucose-induced cell shrinkage. (C) Migratory ability of the EA-hy926 was assessed by performing a wound healing assay. The degree of migration was analyzed by averaging the width of each gap in four places (magnification, x100). The migration rate in the control group was set to $100 \%$. The results are expressed as the mean \pm standard deviation $(\mathrm{n}=4) .{ }^{* *} \mathrm{P}<0.01$, compared with the control group, ${ }^{\#} \mathrm{P}<0.05$ and ${ }^{\# \#} \mathrm{P}<0.01$, compared with the HG group; ${ }^{\$ \$} \mathrm{P}<0.01$, compared with the $\mathrm{HG}+3.44 \mu \mathrm{M}$ vaccarin group; ${ }^{\circ} \mathrm{P}<0.05$ and ${ }^{\text {\& }} \mathrm{P}<0.01$, compared with the $\mathrm{HG}+6.88 \mu \mathrm{M}$ vaccarin group. $\mathrm{HG}, 180 \mathrm{mM}$ high glucose; OD, optical density.

and even cell death (6). The pathogenesis of diabetes mellitus is complicated, and there are several signaling pathways involved in the pathogenesis of diabetes mellitus, including the Notch pathway (12). Notch signaling has been widely implicated in endothelial to mesenchymal transformation, endothelial cell proliferation and the control of apoptosis (25). It has been reported that, in a cultured renal proximal tubular cell model, puromycin aminonucleoside triggers the upregulation of Notch1 signaling components, including Notch intracellular domain and the downstream molecule, Hes1, which is accompanied by the downregulation of Numb, an intrinsic Notch antagonist (26). 
A
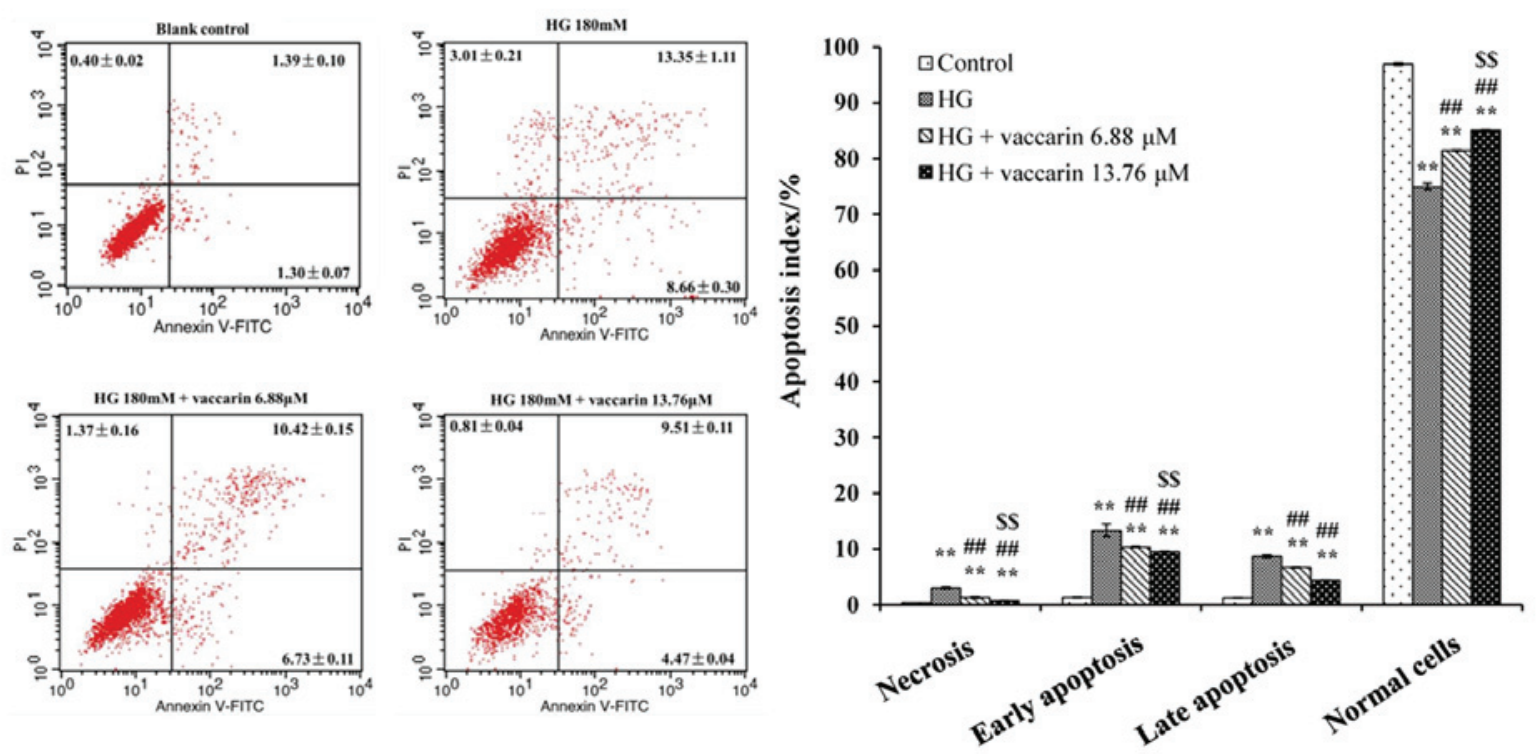

B
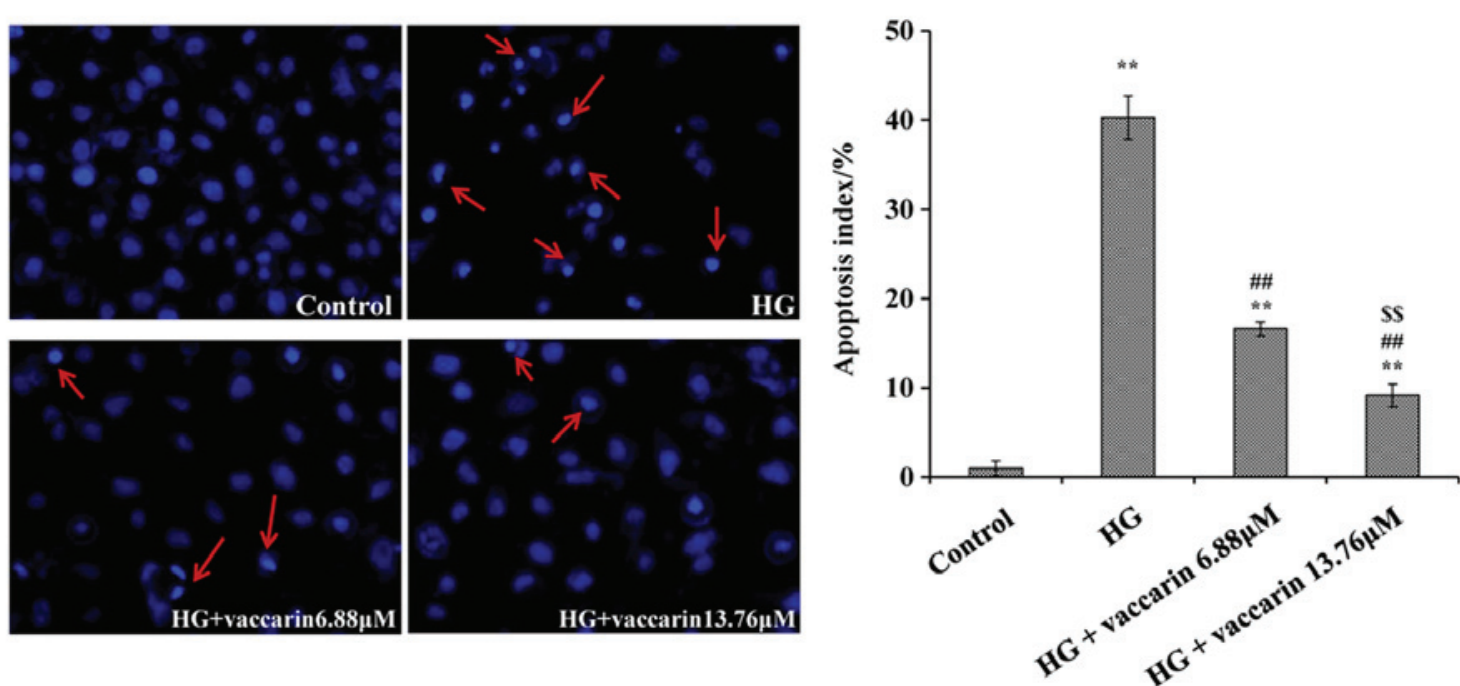

Figure 3. Effects of vaccarin on the apoptotic rate of high glucose-injured EA-hy926 cells treated for $24 \mathrm{~h}$ with $180 \mathrm{mM}$ glucose. (A) Apoptosis of EA-hy926 cells was assessed using an Annexin V-FITC/PI apoptosis detection kit, and expressed as the apoptotic index. (B) Hoechst33342 staining was performed to stain the nuclei of the cells (blue). The morphology of the normal cell nuclei were different from those of the injured cells. The apoptotic index is expressed as the number of positively stained apoptotic cells/total number of cells counted x100\%. Red arrows indicate apoptotic cells. The results are expressed as the mean \pm standard deviation $(\mathrm{n}=4),{ }^{* *} \mathrm{P}<0.01$, compared with the control group; ${ }^{\# \#} \mathrm{P}<0.01$, compared with the HG group; ${ }^{\text {\$\$ }} \mathrm{P}<0.01$, compared with the $\mathrm{HG}+6.88 \mu \mathrm{M}$ vaccarin group. $\mathrm{HG}, 180 \mathrm{mM}$ high glucose; FITC, fluorescein isothiocyanate; PI, propidium iodide.

The results of the present study indicated that, in human EA·hy926 endothelial cells, high glucose causes vascular endothelial cell apoptosis via activating Notch1 and Hes1. In addition, vaccarin was found to impart a protective effect against high glucose induced endothelial injury, which was evidenced by improved cell viability and migratory ability, and a decreased apoptotic index. Therefore, the protective effects of vaccarin against cell injury were, at least in part, dependent on Notch1 inhibition. There are several anti-high glucose-induced cell injury drugs against apoptosis, which act through regulating the cell apoptotic pathway (27). B cell lymphoma (Bcl)2, $\mathrm{Bcl}-2$-associated $\mathrm{X}$ protein, $\mathrm{Bcl}$ antagonist killer 1 and caspase 3, which are important in the process of cell apoptosis, are all important members of the cell survival pathway (28). Caspase 3 has a dominant role in the execu- tion of the apoptotic process, and the activation of caspase 3 is the central link in apoptosis. Previous data have demonstrated that caspase 3 may be an important target involved in ROS-mediated high glucose-induced apoptosis in human endothelial cells (29). In the present study, the results showed that vaccarin effectively suppressed the overexpression of caspase 3 under high glucose conditions.

High glucose-induced free radicals can have irreversible effects on several biomolecules, including lipids, which leads to lipid peroxidation. LDH leakage, corresponding to membrane damage, and MDA, a by-product of lipid peroxidation induced by excessive ROS, are widely used biomarkers of oxidative stress injury (30). Antioxidants, including SOD, are important in providing protection against high glucose injury. In the present study, significant decreases in SOD were observed in 
A

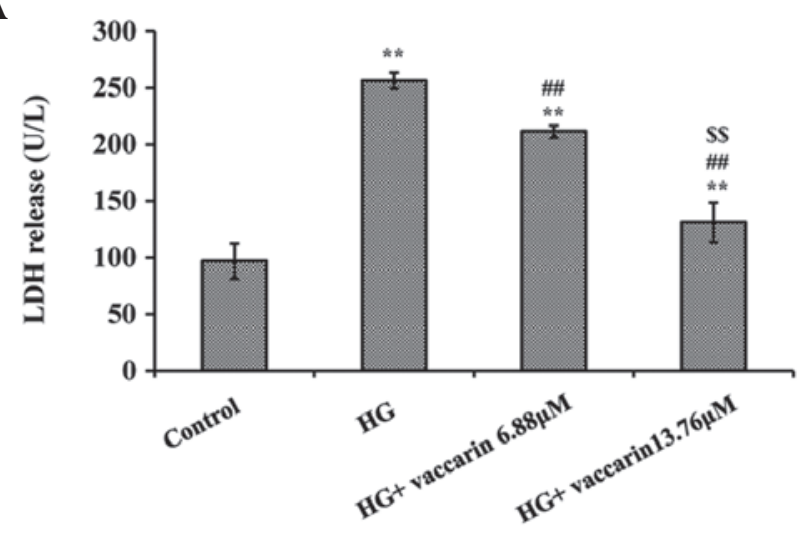

B

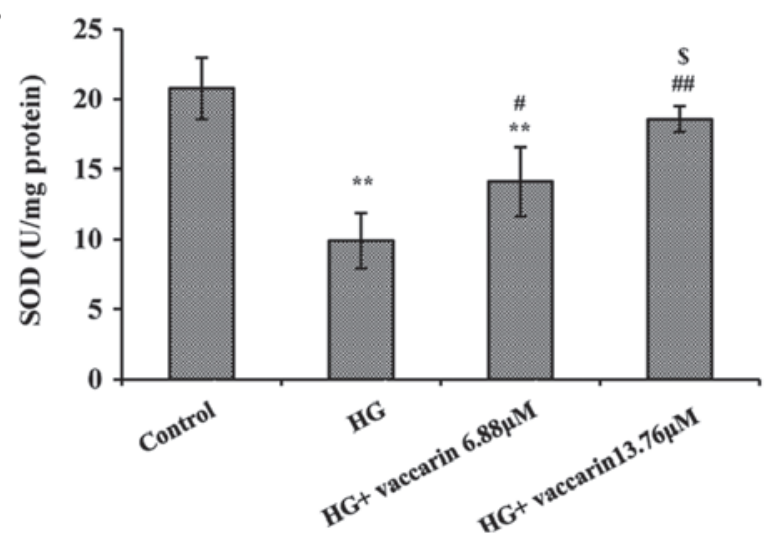

C

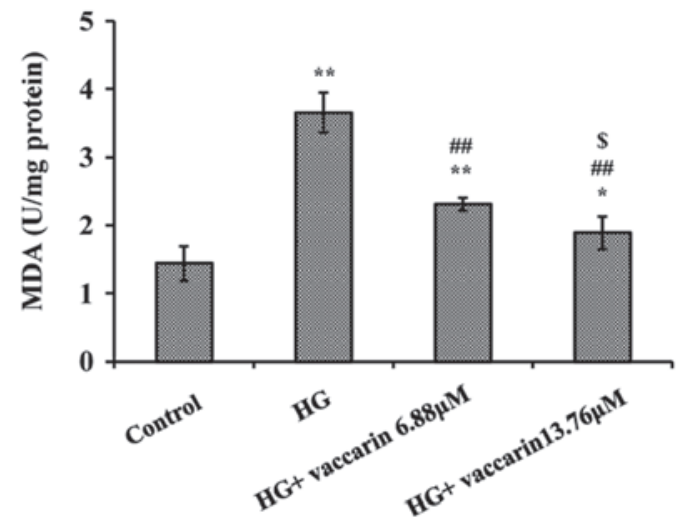

D

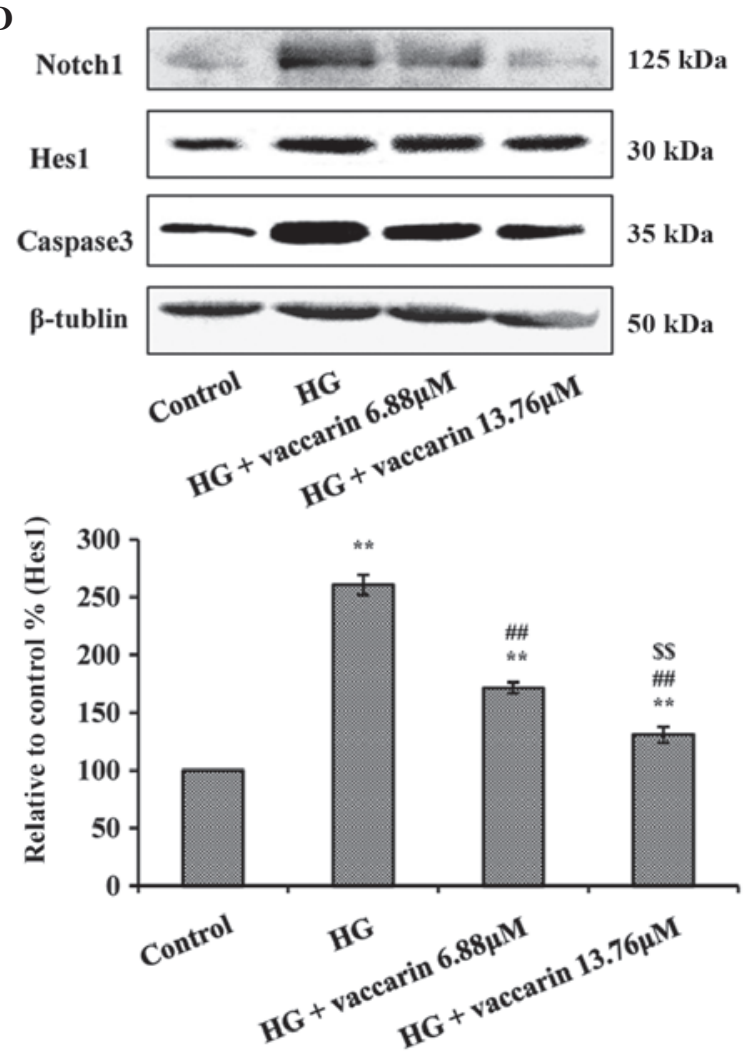

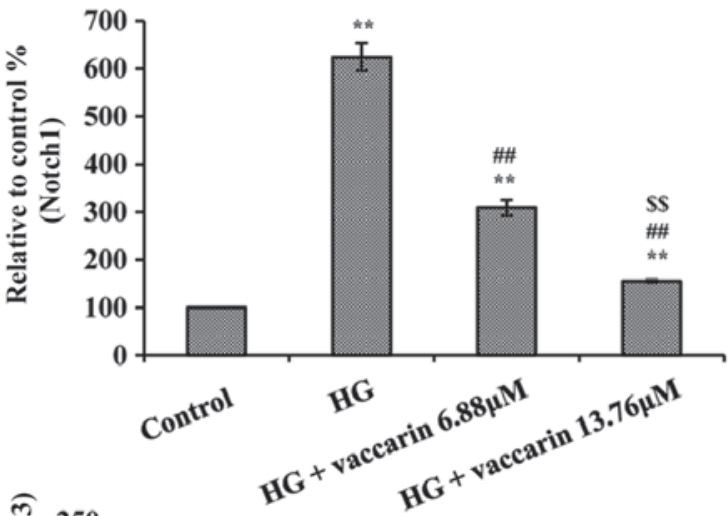

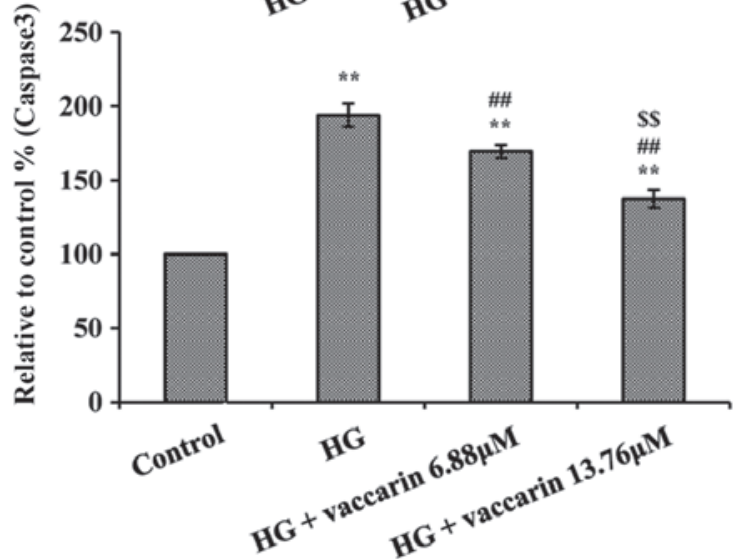

Figure 4. Effects of vaccarin on the intracellular levels of SOD and MDA, and LDH release, and the effects of vaccarin on the expression levels of Notch1, Hes1 and caspase 3 in high glucose-injured EA.hy926 cells. treated for 24 h. (A) Release of LDH in EA.hy926 cells treated with high glucose in the absence or presence of vaccarin. (B) Intracellular levels of SOD in EA.hy926 cells treated with high glucose in the absence or presence of vaccarin. (C) Intracellular levels of MDAin EA·hy926 cells treated with high glucose in the absence or presence of vaccarin. (D) Representative images of Western blots are shown. The results are expressed as the mean \pm standard deviation $(n=4) .{ }^{* *} \mathrm{P}<0.01$, compared with the control group, ${ }^{\#} \mathrm{P}<0.05$ and ${ }^{\# \#} \mathrm{P}<0.01$, compared with the $\mathrm{HG}$ group; ${ }^{\$} \mathrm{P}<0.05$ and ${ }^{\$ \$} \mathrm{P}<0.01$, compared with the $\mathrm{HG}+6.88 \mu \mathrm{M}$ vaccarin group. HG, high glucose; Hes1, Hairy and enhancer of split 1 ; SOD, superoxide dismutase; MDA, malondialdehyde; LDH, lactate dehydrogenase. 
EA·hy926 cells following exposure to high glucose, indicating the impairment in antioxidant defenses. In addition, a marked elevation in MDA production was associated with an increase in the release of LDH. Preincubation with vaccarin was found to protect the EA-hy926 cells against high glucose-induced cellular oxidative injury, as shown by inhibited levels of LDH and MDA, but enhanced the activity of SOD. Notably, in addition to downregulating high glucose-induced Notch signaling, vaccarin treatment downregulated the high glucose-induced apoptotic pathway-associated protein, caspase 3 . Taken together, the results of the present study suggested that the enhancement of endogenous antioxidant preservation and attenuation of the cell apoptotic pathway may represent a major mechanism of cellular protection by vaccarin.

In conclusion, the present study demonstrated that vaccarin prevented apoptosis of human EA-hy926 endothelial cells induced by high glucose. These results indicated that vaccarin may be a possible therapeutic in the prevention of diabetic vascular lesions or atherosclerosis, although further investigations are required.

\section{Acknowledgements}

This study was supported by the Fundamental Research Funds for the Central Universities (grant no. JUSRP51412B).

\section{References}

1. Beckman JA, Creager MA and Libby P: Diabetes and atherosclerosis: Epidemiology, pathophysiology and management. JAMA 287: 2570-2581, 2002.

2. Malakul W, Thirawarapan S, Suvitayavat W and Woodman OL: Type 1 diabetes and hypercholesterolaemia reveal the contribution of endothelium-derived hyperpolarizing factor to endothelium-dependent relaxation of the rat aorta. Clin Exp Pharmacol Physiol 35: 192-200, 2008.

3. Vita JA: Endothelial function and clinical outcome. Heart 91: 1278-1279, 2005.

4. Chen CA, Wang TY, Varadharaj S, Reyes LA, Hemann C, Talukder MA, Chen YR, Druhan LJ and Zweier JL: S-glutathionylation uncouples eNOS and regulates its cellular and vascular function. Nature 468: 1115-1118, 2010.

5. Wu XG and Li L: Rosiglitazone suppresses lipopolysaccharide-induced matrix metalloproteinase- 2 activity in rat aortic endothelial cells via Ras-MEK $1 / 2$ signaling. Intl J Cardiol 158: 54-58, 2012.

6. Baumgartner-Parzer SM, Wagner L, Pettermann M, Grillari J, Gessl A and Waldhausl W: High-glucose-triggered apoptosis in cultured endothelial cells. Diabetes 44: 1323-1327, 1995

7. Liu J, Deng WJ, Fan L, Tian LM, Jin L, Jin Z, Guo Q, Xu Y and $\mathrm{Li} \mathrm{N}$ : The role of radix hedysari polysaccharide on the human umbilical vein endothelial cells (HUVECs) induced by high glucose. Eur J Intern Med 23: 287-292, 2012.

8. Cook KM and Figg WD: Angiogenesis inhibitors: Current strategies and future. Prospects. CA Cancer J Clin 60: 222-243, 2010.

9. Juryńczyk M and Selmaj K: Notch: A new player in MS mechanisms. J Neuroimmunol 218: 3-11, 2010.

10. Androutsellis-Theotokis A, Leker RR, Soldner F, Hoeppner DJ, Ravin R, Poser SW, Rueger MA, Bae SK, Kittappa R and McKay RD: Notch signalling regulates stem cell numbers in vitro and in vivo. Nature 442: 823-826, 2006.
11. McCright B: Notch signaling in kidney development. Curr Opin Nephrol Hypertens 12: 5-10, 2003.

12. Gao F, Yao M, Shi Y, Hao J, Ren Y, Liu Q, Wang X and Duan H: Notch pathway is involved in high glucose-induced apoptosis in podocytes via Bcl-2 and p53 pathways. J Cell Biochem 114: 1029-1038, 2013.

13. Yang J, Han Y, Chen C, Sun H, He D, Guo J, Jiang B, Zhou L and Zeng C: EGCG attenuates high glucose-induced endothelial cell inflammation by suppression of PKC and NF- $\kappa \mathrm{B}$ signaling in human umbilical vein endothelial cells. Life Sci 92: 589-597, 2013.

14. China Pharmacopoeia Committee. Chinese Pharmacopoeia 2010 Edition. China Medical Science and Technology Press, Beijing, China, pp49-50, 2010. (In Chinese).

15. Sang SM, Lao AN and Chen ZL: Chemistry and bioactivity of the seeds of Vaccaria segetalis. Orient Foods Herbs 21: 279-291, 2000.

16. Li F and Liang JY: Research progress of Vaccaria segetalis. Straits Pharm J 3: 1-5, 2007 (In Chinese).

17. Li N, Ma CH and Liu D: Chemical constituents analysis of fried vaccaria segetafis. Chin J Exptl Tradit Med Form 19: 73-75, 2013 (In Chinese).

18. Sun Y, Liang H, Zhang X, Tong H and Liu J: Structural elucidation and immunological activity of a polysaccharide from the fruiting body of Armillaria mellea. Bioresour Technol 100: 1860-1863, 2009.

19. Meng H, Chen Y, Qin W, Tang X and Ye Z: Determination of vaccarin in Vaccariae Semen by HPLC. Zhongguo Zhong Yao Za Zhi 35: 2072-2074, 2010 (In Chinese).

20. Xia MX, Feng L and Zhang LF: Isolation, purification and identification of chemical compound from semen vaccariae to inhibit endothelial cells. Biotechnology Bulletin 2: 93-97, 2009 (In Chinese)

21. Cheong SM, Choi H, Hong BS, Gho YS and Han JK: Dab2 is pivotal for endothelial cell migration by mediating VEGF expression in cancer cells. Exp Cell Res 318: 550-557, 2012.

22. Su Y,Mao N,Li M, Dong X,LinFZ, Xu Y and Li YB: Sarpogrelate inhibits the expression of ICAM-1 and monocyte-endothelial adhesion induced by high glucose in human endothelial cells. Mol Cell Biochem 373: 195-199, 2013.

23. Li B, Qiu T, Zhang P, Wang X, Yin Y and Li S: IKVAV regulates ERK $1 / 2$ and Akt signalling pathways in BMMSC population growth and proliferation. Cell Prolif 47: 133-145, 2014.

24. Meng X, Li ZM, Zhou YJ, Cao YL and Zhang J: Effect of the antioxidant alpha-lipoic acid on apoptosis in human umbilical vein endothelial cells induced by high glucose. Clin Exp Med 8: 43-49, 2008.

25. MacKenzie F, Duriez P, Wong F, Noseda M and Karsan A: Notch4 inhibits endothelial apoptosis via RBP-Jkappa-dependent and -independent pathways. J Biol Chem 279: 11657-11663, 2004.

26. Ding X, Zhu F, Li T, Zhou Q, Hou FF and Nie J: Numb protects renal proximal tubular cells from puromycin aminonucleoside-induced apoptosis through inhibiting Notch signaling pathway. Intl J Biol Sci 7: 269-278, 2011.

27. Stampfer MJ, Hennekens CH, Manson JE, Colditz GA, Rosner B and Willett WC: Vitamin E consumption and the risk of coronary disease in women. N Engl J Med 328: 1444-1449, 1993.

28. Chen SD, Yin JH, Hwang CS, Tang CM and Yang DI: Anti-apoptotic and anti-oxidative mechanisms of minocycline against sphingomyelinase/ceramide neurotoxicity: Implication in Alzheimer's disease and cerebral ischemia. Free Radic Res 46: 940-950, 2012.

29. Ho FM, Liu SH, Liau CS, Huang PJ and Lin-Shiau SY: High glucose-induced apoptosis in human endothelial cells is mediated by sequential activations of c-Jun NH (2)-terminal kinase and caspase-3. Circulation 101: 2618-2624, 2000.

30. Cai Y,Hu X, Yi B, Zhang T and Wen Z: Glucagon-like peptide-1 receptor agonist protects against hyperglycemia-induced cardiocytes injury by inhibiting high mobility group box 1 expression. Molecular Biology Reports 39: 10705-10711, 2012. 